\title{
A ESCRITA DE SURDOS EM AMBIENTE INTERACIONAL DE APRENDIZAGEM MEDIADO PELA LIBRAS
}

\author{
THE WRITING OF THE DEAF IN INTERACTION LEARNING ENVIRONMENT \\ MEDIATED BY LIBRAS
}
LA ESCRITURA DE ALUMNOS CON SORDERA EN AMBIENTE INTERACCIONAL DE APRENDIZAJE MEDIADO POR LENGUA DE SEÑAS (LIBRAS)

Djair Lázaro de Almeida ${ }^{1}$, Cristina Broglia Feitosa de Lacerda ${ }^{2}$

\section{RESUMO}

No presente artigo pretende-se refletir sobre as práticas discursivas que incidiram no processo de escrita em Língua Portuguesa como segunda língua empreendido por sujeitos surdos em contextos interacionais de oficinas. Para tanto, realizou-se um trabalho de reescrita coletiva de uma história de aventura a partir de interações interdiscursivas entre língua de sinais e o português escrito. Investigando a interação entre participantes surdos e educadores ouvintes como elemento que caracterizou o processo de escrita, analisaramse os modos pelos quais as diferentes práticas discursivas se constituíram em ambiente de aprendizagem. No início das oficinas, o educador ouvinte organiza e dirige as interações, promovendo o desenvolvimento das competências expressivas dos participantes surdos, provocando um ambiente propício à aprendizagem. Enquanto mediadores na construção do conhecimento, os educadores ouvintes assumem menos responsabilidades em relação à escrita, estimulando os sujeitos surdos a ocuparem cada vez mais o espaço discursivo. $\mathrm{O}$ caráter dessas interações gera situações favoráveis à autonomia dos participantes surdos. $\mathrm{O}$ que se observou nos movimentos registrados foram os deslocamentos instaurados: do educador como suporte total à confiança depositada nos pares surdos, que se apoiam rumo ao protagonismo na produção de linguagem escrita. Ressalta-se que as práticas e as formações discursivas nas oficinas, voltadas ao desenvolvimento dos mecanismos de produção e compreensão dos discursos, concretizaram-se por meio da língua de sinais como a base para o registro escrito.

PALAVRAS-CHAVE: Surdez. Escrita. Interação

\section{ABSTRACT}

This present article intends to reflect on the discursive practices that focused on the process of writing in Portuguese as a second language, undertaken by deaf individuals, in interactive contexts of workshops. For that, a work of collective rewriting of an adventure story was made, based on interdiscursive interactions between sign language and written Portuguese. Investigating the interaction, between deaf participants and listening educators, as an element that characterized the writing process, we analyzed the ways in which the different discursive practices were constituted in a learning environment. At the beginning of the workshops, the listening educator organizes and directs the interactions promoting the development of the expressive skills of the deaf participants, provoking an environment conducive to learning. As mediators in the construction of knowledge, listening educators assume less responsibility in relation to writing, encouraging deaf subjects to increasingly occupy the discursive space. The character of these interactions generates situations favorable to the autonomy

\footnotetext{
${ }^{1}$ Doutor em Educação Especial - Universidade Federal de São Carlos (UFSCar) - São Carlos, SP - Brasil. Professor Coordenador - Núcleo Pedagógico - Educação Especial. Diretoria de Ensino - São Carlos, SP - Brasil. E-mail: djair lazaro@yahoo.com.br

${ }^{2}$ Doutora em Educação - Universidade Estadual de Campinas (UNICAMP) - Campinas, SP - Brasil. Professora Associada I da Universidade Federal de São Carlos (UFSCar) - São Carlos, SP - Brasil.

E-mail: cristinalacerda@uol.com.br
}

Submetido em: 04/09/2017 - Aceito em: 24/05/2018

(C) ETD- Educação Temática Digital Campinas, SP v.20 n.4 p.1076-1095 out./dez. 2018


of the deaf participants. What was observed in the action recorded was the established displacements: from the educator, as a total support, to the trust deposited in the deaf peers who support themselves towards the protagonism in the production of written language. It should be emphasized that discursive practices and formations in the workshops, aimed at developing the mechanisms of production and understanding of discourses, were materialized through sign language as the basis for written registration.

KEYWORDS: Deafness. Writing. Interaction.

\section{RESUMEN}

El presente artículo busca reflexionar sobre las prácticas discursivas que inciden en el proceso de escritura en lengua portuguesa como segunda lengua, emprendidas por sujetos sordos en contextos interacciónales de talleres. Para ello se realiza un trabajo de reescrita colectiva de una historia de aventura, a partir de interacciones inter-discursivas entre la lengua de señales y el portugués escrito. Al investigar la interacción entre los participantes sordos y los educadores oyentes, como elemento que caracteriza el proceso de escritura, se analizan las formas a través de las cuales las variadas prácticas discursivas se constituyen en ambiente de aprendizaje. Al inicio de los talleres el educador oyente organiza y dirige las interacciones promoviendo el desarrollo de las competencias expresivas de los participantes sordos, provocando un ambiente propicio al aprendizaje. Los educadores oyentes, como mediadores en la construcción del conocimiento, asumen menos responsabilidad en relación a la escritura, estimulando a los sujetos sordos a ocupar, cada vez más, el espacio discursivo. El carácter de esas interacciones origina situaciones favorables a la autonomía de los participantes sordos. El registro realizado permite observar el desplazamiento ocurrido: del educador como soporte total, a la confianza depositada en los pares sordos que se apoyan rumbo al protagonismo en la producción de la lengua escrita. Se destaca que las prácticas y las formaciones discursivas en los talleres, giradas al desarrollo de los mecanismos de producción y comprensión de los discursos, se concretizan por medio de la lengua de señas como base para el registro escrito.

PALABRAS CLAVE: Sordera. Escritura. Interaciones.

\section{INTRODUÇÃO}

A defesa de uma política educacional de inclusão, voltada aos alunos público-alvo da educação especial, ganha força enquanto processo de mobilização social a partir da década de 1990. Este movimento aponta para a necessidade de uma nova escola capaz de abarcar a diversidade de alunos que tomam, com todos os direitos, seus lugares nos bancos escolares. O fato impõe uma revisão, não só nos currículos, como também nas práticas pedagógicas. É necessário, portanto, criar condições a esse novo público para o acesso, permanência e continuidade dos estudos. Como parte desse grupo, o aluno surdo - encorajado pela prática de inclusão - também chega à escola regular, a escola de ouvintes.

Entretanto, a efetivação de uma educação de qualidade para o aluno surdo perpassa questões sociais e pedagógicas, conclamando especial atenção. Pesquisas desenvolvidas no Brasil e no exterior (LACERDA, 2006; FERNANDES, 2011; SVARTHOLM, 2014) revelam um número expressivo de sujeitos surdos que, após percorrer anos de escolarização, apresentam competências acadêmicas aquém daquelas apresentadas por alunos ouvintes, a despeito de suas capacidades cognitivas iniciais serem semelhantes. Dessa forma, as dificuldades de aprendizagem apresentadas pelos alunos surdos podem ser derivadas do modo e das condições de ensino, revelando a necessidade de ações educativas que assegurem o pleno desenvolvimento destes. Nesse sentido, Svartholm (2014) informa que o ambiente comunicativo e interativo em sala de aula é de fundamental importância para a aprendizagem

(C) ETD- Educação Temática Digital Campinas, SP $\quad$ v.20 n.4 $\quad$ p.1076-1095 out./dez. 2018 
de qualquer criança, seja surda ou ouvinte. Assim, conclui a autora, o encontro com a língua, o uso individual da língua e a maneira como a informação é passada para a criança são elementos que concorrem para seu desenvolvimento linguístico e cognitivo.

Outros pesquisadores da área da surdez ainda se debruçam sobre as interações entre professores ouvintes e alunos surdos e sobre como tais interações, enquanto formação discursiva, refletem na aprendizagem como suporte aos mecanismos dos quais os sujeitos surdos lançam mão para a produção textual escrita (FÉLIX, 2009; STREIECHEN; KRAUSELEMKE, 2014).

Nessa direção, no presente artigo pretende-se refletir sobre as práticas e as formações discursivas que incidiram no processo de escrita em Língua Portuguesa como segunda língua empreendido por sujeitos surdos em contextos interacionais de oficinas.

Para tanto, realizaram-se oficinas envolvendo um trabalho de reescrita coletiva de uma história de aventura, a partir de interações interdiscursivas entre língua de sinais e o português escrito. Buscou-se analisar a interação entre participantes surdos e educadores ouvintes como elemento que caracterizou o processo de produção textual escrita. Assim, o propósito deste trabalho foi documentar em pormenores o desdobrar das cenas cotidianas das oficinas, identificando a natureza das interações ali estabelecidas. De acordo com Erickson (2001, p. 16), "os ambientes de aprendizagem são constituídos recursivamente pelas práticas discursivas do cotidiano da sala de aula". Dessa forma, a documentação dos eventos singulares das oficinas concretizou-se como meio de analisar como a natureza interacional reverberou na aprendizagem dos participantes surdos. Esse tipo de análise revela, no parecer de Erickson (2001, p.16), um "nível de especificidade analítica que pode sugerir maneiras de mudar, para melhor, as práticas pedagógicas e curriculares".

\section{CONCEPÇÃO BAKHTINIANA DE LÍNGUA E LINGUAGEM}

Interessa-nos, aqui, o conceito de linguagem como processo de interação verbal, ou seja, a linguagem como lugar de interação humana, de construção de relações sociais e de constituição de sujeitos e, portanto, dialógica. Tal maneira de conceber a linguagem reflete diretamente no encaminhamento do processo educativo, em geral, e, especificamente, do aluno surdo, uma vez que a linguagem assim considerada direciona o ensino de língua portuguesa por um viés discursivo enunciativo. Trata-se, portanto, de focalizar, no ambiente escolar, como apontam Rojo e Cordeiro (2010, p. 10), "o texto em seu funcionamento e em seu contexto de produção/leitura, evidenciando as significações geradas mais do que as propriedades formais que dão suporte a funcionamentos cognitivos".

Contrariando o ensino que privilegia a análise estritamente gramatical, tal direcionamento enseja a aprendizagem da língua em situação de comunicação, uma vez que esta é assimilada graças aos enunciados concretos utilizados e reproduzidos em comunicação

(C) ETD- Educação Temática Digital Campinas, SP $\quad$ v.20 n.4 $\quad$ p.1076-1095 out./dez. 2018 
efetiva. A consciência linguística dos falantes "nada tem a ver com o sistema abstrato de formas normativas", mas sim com a linguagem enquanto "conjunto dos contextos possíveis de uso de cada forma particular" (BAKHTIN/VOLOCHINOV, 2010, p. 98). Nesse sentido, aprender uma língua significa, para Bakhtin (2006), aprender a construir enunciados, uma vez que os sujeitos não falam por orações e palavras isoladas. Dessa forma, o aprendizado da Língua Portuguesa resulta de um movimento de construção fundado nas relações que os sujeitos estabelecem com seus interlocutores, com os fatos e com os acontecimentos, a partir da língua em uso. Ou seja, a apropriação de uma língua se faz por meio da interação verbal.

Nesse contexto, investir em um processo de ensino e aprendizagem a partir da interação discursiva pode fazer sentido, uma vez que a enunciação é de natureza social e interacional, ou seja, as formas da língua são assimiladas na estrutura concreta da enunciação, como signos variáveis e flexíveis, e não no sistema abstrato, como forma sempre idêntica. As formas linguísticas se mostram, aos locutores, sempre mergulhadas em enunciações e contextos precisos (BAKHTIN; VOLOCHINOV, 2010).

A escolha da concepção teórica que alicerça este trabalho se deve ao fato de a interação verbal, no parecer de Bakhtin (2006), ser fator constitutivo dos sujeitos. Nesse sentido, pode-se dizer que o outro tem um papel de realce na intermediação da aprendizagem, já que qualquer evento de linguagem representa sempre uma atualização das relações entre sujeitos situados historicamente. Para a teoria da interação verbal, a linguagem é uma atividade sociocultural compreendendo práticas discursivas em um jogo de relações dialógicas, uma vez que toda palavra se constitui no produto da interação dos falantes, que se definem um em relação ao outro (BAKHTIN/; VOLOCHINOV, 2010). Assim, o modo como as práticas discursivas se estabelecem na relação professor e aluno pode ser determinante no processo de aprendizagem, uma vez que os sujeitos se projetam a partir dos discursos do outro. As múltiplas relações estabelecidas entre os diferentes sujeitos são marcadas por valores individuais engendrando diferentes possibilidades enunciativas.

Dessa forma, consideramos que uma metodologia de ensino de língua que pressuponha o uso efetivo da linguagem entre sujeitos que agem em um processo vivo e concreto de interação pode levar os aprendizes mais facilmente à percepção das determinações sociais da comunicação, do valor das unidades linguísticas e de seus diferentes recursos.

Levar tal concepção à educação de surdos implica em entender que, para estes, "a linguagem escrita da língua portuguesa precisa ser vivenciada em sua forma viva" e ser colocada em diálogo com a língua de sinais "em sua dinâmica dialógica e interdiscursiva, a fim de que os processos socioculturais, históricos e ideológicos que lhes são constitutivos possam ser (re)significados" (LODI; BORTOLOTTI; CAVALMORETTI, 2014, p. 134). As autoras compreendem que uma maneira de favorecer esse processo é oferecer aos alunos surdos

(C) ETD- Educação Temática Digital Campinas, SP $\quad$ v.20 n.4 $\quad$ p.1076-1095 out./dez. 2018 
práticas de leitura e produção textual em Língua Brasileira de Sinais (Libras) para que esse conhecimento possa, posteriormente, ser colocado em diálogo com o português. Tais práticas convergem para a proposta educacional bilíngue, que traz como principal fundamento a língua de sinais como base linguística para o ensino e a aprendizagem do português escrito como segunda língua.

Partindo do conceito de linguagem como movimento constitutivo de natureza dialógica e como um processo que se efetiva na interação verbal, se depreende que o aprendizado de língua se dá pelo fenômeno social da interação e não apenas por seu sistema autônomo, de modo que a construção conjunta do conhecimento em outra língua poderia levar os participantes surdos para além dos conhecimentos já adquiridos. Dessa forma, partimos da hipótese de que as oficinas poderiam, por meio do outro/interlocutor, estimular as ações comunicativas entre os participantes surdos e educadores ouvintes, abrindo mais possibilidades de aprendizagem.

\section{METODOLOGIA: PROCEDIMENTOS DE PESQUISA}

Os pressupostos que ampararam o trabalho de campo da presente pesquisa assentaram-se nas concepções bakhtinianas de língua. Para a realização desta, propuseramse oficinas de português como segunda língua para surdos, desenvolvidas na Universidade Federal de São Carlos (UFSCar). Respondendo a propostas da educação bilíngue para surdos, as oficinas se configuraram a partir de um trabalho com história de aventura, privilegiando interações discursivas em Libras.

A aquisição da escrita, imersa no processo de aquisição da linguagem, tem para o surdo um caminho diverso daquele do ouvinte - enquanto este reconstrói a história de sua relação com a linguagem por meio da língua oral, o surdo percorre tal caminho orientandose pela língua de sinais (SILVA, 2014; PEREIRA et al., 2003).

As abordagens e os procedimentos aqui adotados em relação ao estudo meticuloso da interação e do discurso nas oficinas aproximam-se, de diversas maneiras, dos métodos da etnografia e da microetnografia educacional. De acordo com Erickson (2001, p. 12), "os propósitos essenciais dessas abordagens são documentar em detalhe o desenrolar dos eventos cotidianos" para desvendar "os significados atribuídos a eles tanto por aqueles que deles participam, quanto por aqueles que os observam".

\footnotetext{
O trabalho idealmente envolve observação e participação de longo prazo no cenário que está sendo estudado com a finalidade de propiciar familiarização com os padrões rotineiros da ação e interpretação que constituem o mundo cotidiano local dos participantes. A ênfase nessa pesquisa é descobrir tipos de coisas que fazem a diferença na vida social; ênfase na qualitas mais do que na quantitas (ERICKSON, 2001, p. 12).
} 
Nosso estudo, por ser uma observação participante de longo prazo, permite a familiarização com os referidos padrões rotineiros, possibilitando responder questionamentos como "qual é a gama completa de variação dos significados implícitos e explícitos atribuídos a essas várias ações pelos vários atores sociais nelas engajados?" (ERICKSON, 2001, p. 13).

\section{O contexto das oficinas}

No segundo semestre de 2011, reuniu-se nas dependências da UFSCar, sob a direção de uma doutoranda do Programa de Pós-Graduação em Educação Especial, um grupo de surdos interessados em aprofundar seus conhecimentos em Língua Portuguesa escrita. 0 referido grupo, composto por surdos jovens e adultos egressos ou em fase final de Ensino Médio e por alunos do Ensino Fundamental - anos finais -, trazia, em comum, histórias de um modelo escolar que, não atendendo às necessidades específicas em seu processo de alfabetização, acabou estabelecendo limitações em relação à leitura e à escrita. É importante salientar que o processo de alfabetização da maioria desses sujeitos surdos não ocorreu em circunstâncias favoráveis, uma vez que estes não vivenciaram o português como segunda língua e nem contaram como apoio de tradutores e intérpretes de Libras.

Com o intuito de desenvolver junto ao grupo atividades de leitura e de escrita, a proposta de oficinas de português como segunda língua concretizou-se como um projeto de longa duração envolvendo outros pesquisadores na área da surdez e uma graduanda do curso de Licenciatura em Educação Especial da UFSCar. Assim, o grupo, que contava com um número oscilante de participantes, buscava nesse espaço oportunidade para avançar nos conhecimentos em português que não se mostravam suficientes com as práticas escolares.

Baseada em um trabalho com diferentes gêneros, a proposta pedagógica das oficinas calcou-se na relevância da interação entre os participantes para a construção de sentidos pelos sujeitos. As atividades desenvolvidas permitiam que os sujeitos surdos partilhassem conhecimentos por meio da língua de sinais em busca da aprendizagem da língua portuguesa escrita, como segunda língua.

A despeito de essas atividades terem se iniciado no segundo semestre de 2011, o período de desenvolvimento das oficinas, ao qual se reporta esta pesquisa, compreende os anos de 2013 e 2014. Dessa forma, os trabalhos foram desenvolvidos em torno de 54 oficinas, de 21 de fevereiro de 2013 a 4 de dezembro de 2014.

Participantes surdos da pesquisa

O grupo era composto de sete participantes surdos em uma faixa etária entre 14 e 30 anos, conforme sintetizado no quadro a seguir.

(C) ETD- Educação Temática Digital Campinas, SP $\quad$ v.20 n.4 $\quad$ p.1076-1095 out./dez. 2018 
QUADRO 1 - Participantes surdos

\begin{tabular}{|c|c|c|c|c|c|}
\hline Nome & $\begin{array}{c}\text { Faixa } \\
\text { etária }\end{array}$ & Escolarização $^{1}$ & $\begin{array}{c}\text { Fase da perda da } \\
\text { audição }\end{array}$ & $\begin{array}{c}\text { Conhecimento em } \\
\text { Libras (inicial) }\end{array}$ & $\begin{array}{c}\text { Conhecimento em } \\
\text { Português escrito }\end{array}$ \\
\hline $\begin{array}{c}\text { Denis } \\
\text { (P1) }\end{array}$ & 14 & $\begin{array}{c}\text { 8o ano EF em escola } \\
\text { bilíngue }\end{array}$ & Pré-linguística & $\begin{array}{c}\text { Pouco } \\
\text { conhecimento }\end{array}$ & $\begin{array}{c}\text { Conhecimento } \\
\text { básico }{ }^{2}\end{array}$ \\
\hline $\begin{array}{c}\text { Dalton } \\
\text { (P2) }\end{array}$ & 14 & $\begin{array}{c}80 \text { ano do EF em escola } \\
\text { bilíngue }\end{array}$ & Pré-linguística & $\begin{array}{c}\text { Pouco } \\
\text { conhecimento }\end{array}$ & $\begin{array}{c}\text { Conhecimento } \\
\text { básico }\end{array}$ \\
\hline $\begin{array}{c}\text { Wilson } \\
\text { (P3) }\end{array}$ & 30 & EF completo & Pré-linguística & $\begin{array}{c}\text { Conhecimento } \\
\text { precário }\end{array}$ & $\begin{array}{c}\text { Pouco } \\
\text { conhecimento }\end{array}$ \\
\hline $\begin{array}{c}\text { Wesley } \\
\text { (P4) }\end{array}$ & 30 & EF completo & Pré-linguística & Fluente & $\begin{array}{c}\text { Pouco } \\
\text { conhecimento }\end{array}$ \\
\hline $\begin{array}{c}\text { Janaína } \\
\text { (P5) }\end{array}$ & 17 & $\begin{array}{c}\text { 10 ano do EM em } \\
\text { escola regular (sem } \\
\text { intérprete) }\end{array}$ & $\begin{array}{c}\text { Perda gradual a } \\
\text { partir dos nove } \\
\text { anos de idade }\end{array}$ & $\begin{array}{c}\text { Pouco } \\
\text { conhecimento }\end{array}$ & $\begin{array}{c}\text { Conhecimento } \\
\text { intermediário }\end{array}$ \\
\hline $\begin{array}{c}\text { Miguel } \\
\text { (P6) }\end{array}$ & 27 & EM completo & Pré-linguística & $\begin{array}{c}\text { Pouco } \\
\text { conhecimento }\end{array}$ & $\begin{array}{c}\text { Pouco } \\
\text { conhecimento }\end{array}$ \\
\hline $\begin{array}{c}\text { Júlia } \\
\text { (P7) }\end{array}$ & 16 & $\begin{array}{c}80 \text { ano do EF em escola } \\
\text { bilíngue }\end{array}$ & Pré-linguística & Bom conhecimento & $\begin{array}{c}\text { Conhecimento } \\
\text { básico }\end{array}$ \\
\hline
\end{tabular}

1 EF - Ensino Fundamental / EM - Ensino Médio

2 Conhecimento precário das estruturas da Língua Portuguesa que prejudica a comunicação escrita.

3 Conhecimento de vocabulário e da estrutura gramatical em Língua Portuguesa que permite enfrentar situações de escrita com relativa segurança, porém, com dificuldade.

Fonte: Elaborado pelos autores.

Todos frequentaram as oficinas no decorrer do ano de 2013, com exceção de Júlia, que iniciou sua participação no ano de 2014. Cumpre salientar que no ano de 2014 as atividades desenvolveram-se somente com a participação de Denis, Dalton e Júlia. Por desavenças particulares, Wesley e Miguel deixaram de participar das oficinas. A participação de Janaína foi interrompida devido ao ingresso em um curso de Pedagogia noturno. Por sua vez, Wilson também deixou de participar das atividades das oficinas por problemas familiares e incompatibilidade de horários.

No início das atividades, Janaína frequentava o Ensino Médio em uma escola sem intérprete educacional e manifestava o desejo de cursar Pedagogia.

Miguel frequentava as oficinas regularmente, com alta frequência, e ingressou no grupo com o intuito de melhorar os conhecimentos em português escrito para conseguir a carteira nacional de habilitação.

Denis, assíduo nas oficinas, frequentava, havia alguns meses, uma escola com proposta bilíngue. Dalton também frequentava assiduamente as atividades das oficinas e demonstrava relativa segurança na compreensão das línguas. Wilson, utilizando gestos caseiros no início das oficinas, repetia o histórico de grande parte dos surdos egressos da educação básica, sem condições mínimas de ler e escrever pequenos textos. Trabalhador na área da indústria, partilhava com Miguel o sonho de conseguir a carteira de motorista. 
Wesley, com baixa frequência nas atividades das oficinas, também trabalhador da indústria, tinha a intenção de retornar aos estudos e terminar o Ensino Médio, no período noturno, na modalidade de Educação de Jovens e Adultos (EJA). Júlia iniciou sua participação nas oficinas no ano de 2014, quando foi matriculada no 8 o ano do Ensino Fundamental, na mesma escola com proposta bilíngue que Denis e Dalton frequentavam.

Todos os participantes, com exceção de Janaína, que apresentou perda gradual de audição no período pós-linguístico e, portanto, trazia conhecimentos intermediários do português, foram frutos de uma escola que não atendeu a suas particularidades linguísticas durante a fase de alfabetização (séries iniciais) e não dominavam a língua portuguesa escrita dentro dos parâmetros esperados para a idade.

Torna-se importante registrar o fato de Janaína ter desenvolvido a linguagem a partir do português oral, cuja interlocução com outros falantes da língua colaborou para que sua linguagem fluísse, provendo atitudes discursivas, que, de certa forma, propiciaram a apropriação de elementos socioculturais e linguísticos em uma fase importante de seu desenvolvimento. A despeito desses registros linguísticos, a perda gradual da audição fez com que Janaína incorporasse informações do mundo e aspectos da linguagem de forma fragmentada, fato observado em sua dificuldade quanto à significação de conceitos, revelando, por vezes, a cristalização de formas linguísticas, de modo mecânico, sem a compreensão global e o alcance dos diferentes significados da mesma maneira que os demais participantes surdos. O conhecimento restrito da língua de sinais, devido ao recente contato com essa língua, levava, muitas vezes, Janaína a interagir em português oral com os pesquisadores, em detrimento da comunicação com os pares surdos na construção de conceitos.

\section{Educadores ouvintes}

As oficinas foram coordenadas por um dos autores deste artigo, contando com a participação de pesquisadores da área da surdez, aqui denominados de Educadores, os quais serão indicados por Luna (E1), Milena (E2), Danilo (E3), Adriano (E4) e Katy (E5) quando da transcrição, apresentação e análise dos dados. Todos têm conhecimentos em Libras e formação no campo da Educação ou de Letras.

\section{A coleta de dados}

Com o objetivo de analisar os episódios interativos que poderiam revelar as relações interpessoais e as práticas durante as oficinas, optou-se pela videogravação para registrar os trabalhos. Tal procedimento, permitindo a captação dos processos e posterior análise das interações e da língua em uso, pode revelar determinadas singularidades que os sujeitos surdos esboçam em suas produções escritas, bem como as soluções que buscam para a transição de línguas e a exploração da língua de sinais como parâmetro para a construção dessa escrita. Para a coleta de dados, lançou-se mão, também, do diário de campo.

(C) ETD- Educação Temática Digital Campinas, SP $\quad$ v.20 n.4 $\quad$ p.1076-1095 out./dez. 2018


De acordo com Erickson (2001), o pesquisador pode se valer de dois meios primários de coleta de dados: "observar e perguntar". Isso pode gerar diferentes fontes e tipos de dados, como notas de campo, bem como as videogravações, que se tornam, segundo ao autor, "a base para transcrições de comportamento verbais e não verbais", cada qual apresentando "um status epistemológico diferente como evidência" (ERICKSON, 2001, p. 13).

Focalizando aspectos dialógicos da interação entre sujeitos, o material documentado por videogravação foi recortado em episódios considerados significativos para o propósito desta pesquisa, buscando delinear o curso das transformações: o processo de formação dos sujeitos quanto à leitura e à escrita em relações estabelecidas nas oficinas de português como segunda língua para surdos.

Os episódios que constituem o corpus de análise foram selecionados considerando o contexto comunicativo (para quê escrever, para quem escrever e como escrever) na realização da reescrita coletiva de uma história de aventura. Os trechos dos episódios cujas enunciações se apresentaram significantes em relação às estratégias de produção, revisão e reflexão da língua coletivamente foram traduzidos da Libras para a Língua Portuguesa escrita.

Para viabilizar esse processo de coleta de dados, foram utilizadas duas câmeras filmadoras. Uma delas registrava as ações dos participantes surdos, permanecendo estática, uma vez que estes se posicionavam sentados em frente à tela de projeção/lousa, enquanto a outra se movimentava de acordo com a localização dos pesquisadores e dos próprios participantes surdos, capturando as interações, quando estes se posicionavam frente à lousa para a reescrita. Além desses equipamentos específicos para as filmagens, utilizaram-se, durante as oficinas, computadores, projetor, lousa/tela de projeção, mesas, cadeiras e blocos flip chart para a montagem de um dicionário portátil que era exposto e alimentado por palavras, de acordo com a necessidade do grupo.

\section{DESENVOLVIMENTO DAS OFICINAS}

As atividades das oficinas desenvolviam-se uma vez por semana, com duração de uma hora e meia, tendo como locação uma sala de estudos da UFSCar, sendo videogravadas por uma auxiliar de pesquisa. Ao final de cada atividade diária, os educadores discutiam os encaminhamentos para a próxima semana em relação ao planejamento do trabalho, preparação e produção de materiais e as estratégias didáticas visando ao desenvolvimento da linguagem dos participantes surdos. No decorrer da semana, as anotações, os registros e as ocorrências das atividades, a partir do diário de bordo, eram partilhados entre os pesquisadores, via e-mail.-Assim, discutia-se sobre as atividades que melhor atenderiam às necessidades do grupo. Nesse sentido, as oficinas não obedeciam a um cronograma fixo e o planejamento não se submetia a metas curriculares, sendo, pois, as sequências didáticas agenciadas por um planejamento que privilegiava múltiplas oportunidades de interlocução e de diferenciação de ensino. Os trabalhos das oficinas norteavam-se por atividades cujos

(C) ETD- Educação Temática Digital Campinas, SP $\quad$ v.20 n.4 $\quad$ p.1076-1095 out./dez. 2018


rumos, muitas vezes imprevistos, eram ditados pelos próprios participantes surdos, à medida que revelavam suas dificuldades, ou ainda, pelas soluções que estes encontravam como agentes do processo de ensino e aprendizagem.

Buscando a natureza interativa da linguagem e com o intuito de inserir os sujeitos surdos em práticas de leitura e escrita, optou-se por um trabalho a partir de uma história de aventura, priorizando contextos significativos que avultassem a funcionalidade da Língua Portuguesa escrita. A proposta partiu dos educadores, porém, direcionados pelos próprios participantes surdos, que demonstraram grande interesse em histórias de aventura em atividades preliminares desenvolvidas nas oficinas. A história de aventura "As sete viagens de Simbad, o marujo" (HOLEINONE, 1998), tendo certa estrutura definida por sua função, se caracteriza por abarcar um plano comunicacional, ou seja, uma forma de linguagem prescritiva que possibilita e favorece, no parecer de Schneuwly (2010), a produção e compreensão textual.

Conforme apontam os estudos de Lodi (2013, p. 176), no universo do aluno surdo, "conhecer um determinado gênero discursivo em língua portuguesa significa ter contato de forma significativa com ele, inicialmente em Libras e posteriormente em português", e tal relação com a segunda língua deve se dar inicialmente pela leitura. Partindo desse pressuposto, criou-se um material didático com a elaboração de um vídeo de "As sete viagens de Simbad, o marujo", narrado em Libras por uma doutoranda do programa de Educação Especial, ouvinte bilíngue. Embora a potencialidade visual não seja característica inerente e única da língua de sinais, esta foi explorada a partir de fotografias e gravuras que ilustraram o vídeo. Privilegiar uma pedagogia que considerasse as especificidades dos alunos surdos foi muito importante, uma vez que eles "se encontram imersos no mundo visual e apreendem, a partir dele, a maior parte das informações para a construção de seu conhecimento" (LACERDA; SANTOS; CAETANO, 2013, p. 186).

Após retomar o vídeo várias vezes e os participantes surdos narrarem a história em Libras, exibiu-se na tela o texto escrito digitalizado. Considerando, inicialmente, o discurso já construído em língua de sinais, os sujeitos surdos foram colocados em situação de leitura, buscando um diálogo entre línguas, uma vez que a prática de leitura pressupõe um intercâmbio com conhecimentos construídos anteriormente, no qual a presença de outros textos e enunciações não pode ser ignorada.

Só após esse intenso trabalho de leitura deu-se início à produção textual escrita. Fruto de uma enunciação, a escrita pressupôs uma anterior elaboração da linguagem a partir de informações advindas da leitura, remetendo os participantes surdos diretamente aos contextos manipulados anteriormente. Dessa forma, a reescrita do texto pelos surdos veio como materialização do processo de construção de sentidos a partir da leitura.

(C) ETD- Educação Temática Digital Campinas, SP $\quad$ v.20 n.4 $\quad$ p.1076-1095 out./dez. 2018 
Tomando a escrita como objeto de reflexão e supondo que o exercício coletivo pode favorecer a manifestação de saberes individuais de uma forma mais segura, uma vez que as trocas entre pares imprimem dinamismo ao conhecimento, iniciou-se a reescrita, a várias mãos, da história de aventura estudada. Propôs-se, então, a seguinte situação didática: narração, em Libras, pelos surdos com destino textual escrito, por outros surdos.

\section{A interação entre participantes surdos e educadores ouvintes nas oficinas}

Investigando a interação entre participantes surdos e educadores ouvintes como elemento que caracterizou o processo de produção textual escrita, analisamos os modos pelos quais as diferentes práticas e formações discursivas se constituíram em ambiente de aprendizagem. Para tanto, na análise dos recortes dos episódios aqui apresentados, ressaltamos as circunstâncias de reflexão da linguagem nas diferentes práticas discursivas no cotidiano das oficinas.

Buscamos, nos episódios analisados, cenas de interação que indicaram a movimentação dos participantes surdos e dos educadores ouvintes, bem como as repercussões do dizer de cada um sobre o outro durante o processo de reescrita coletiva. Realçando os modos pelos quais as relações dialógicas se estabeleceram nas oficinas, apresentamos amostras das transformações que acometeram as interações, desde o educador dando a palavra final, passando pelo trabalho de transferência, atribuindo aos surdos o papel de sabedores, até o destaque e visibilidade que os surdos adquirem protagonizando o processo de escrita entre os pares que somam saberes.

Voltados para essas reflexões, analisamos, por meio das cenas destacadas, como as interações estabelecidas nas oficinas reverberaram na aprendizagem dos participantes surdos.

\section{Com a palavra final, o educador}

A atividade de produção textual é grifada, no início, pela figura do educador como referência. Tal processo faz parte do desenvolvimento dos participantes surdos enquanto sujeitos da linguagem, uma vez que, para se constituírem como tal, precisam, inicialmente, do outro como modelo de escrita. A cena 1, coletada entre as primeiras oficinas estudadas e transcrita a seguir no Quadro 2, ilustra o papel do educador dirigindo os movimentos da interlocução. 
QUADRO 2 - Transcrição da cena 1

\begin{tabular}{|c|c|c|c|}
\hline $\begin{array}{l}\text { Quem } \\
\text { sinaliza }\end{array}$ & Tradução & $\begin{array}{l}\text { Para } \\
\text { quem } \\
\text { sinaliza }\end{array}$ & $\begin{array}{l}\text { Texto escrito } \\
\text { produzido pelos } \\
\text { participantes surdos } \\
\text { Escriba: P1 }\end{array}$ \\
\hline E2 & $\begin{array}{l}\text { O homem entrou pelo portão e avistou } \\
\text { árvores altas, flores e uma fonte de água, } \\
\text { depois ele avistou um grupo, quem eram essas } \\
\text { pessoas? }\end{array}$ & Todos & \\
\hline P5 & Fonte de água. & E2 & \\
\hline E2 & Que grupo ele viu? & Todos & \\
\hline P5 & Os homens com roupa elegante. & E2 & \\
\hline E2 & Viu o que ela disse? & P1 & \\
\hline P1 & Vi. & E2 & \\
\hline E2 & Homem com roupa elegante. & P1 & Homem \\
\hline P5 & Roupa elegante. & E2/P1 & \\
\hline E2 & Ele viu homem com roupa elegante. & P1 & \\
\hline $\mathrm{P} 2$ & Muitos homens ou um? & P1 & \\
\hline P5 & Elegante, roupa elegante. & E2 & Ele viu homem \\
\hline P3 & Muitos homens ou um homem? & P1 & \\
\hline P3 & Muitos homens com roupa elegante & P1 & \\
\hline P5 & Roupa elegante & P1 & \\
\hline P2 & Um homem ou muitos homens? & P5 & \\
\hline P5 & Roupa elegante & P1 & \\
\hline E3 & $\begin{array}{l}\text { Então, mas você viu o que ele perguntou? Um } \\
\text { homem, não, muitos homens. }\end{array}$ & P5 & \\
\hline P4 & Só um? & E3 & \\
\hline P5 & Não, vários homens. & P2 & \\
\hline E3 & Ó, ela falou que são vários. & P1 & \\
\hline P2 & Apaga homem e escreve O-S homens. & P1 & \\
\hline P3 & Apaga sim. & P1 & Ele viu os homens \\
\hline P2 & Roupa. & P1 & $\begin{array}{l}\text { Ele viu os homens } \\
\text { roupa }\end{array}$ \\
\hline
\end{tabular}

Fonte: Elaborado pelos autores.

Na cena descrita, pode-se observar a reflexão de cada um marcada pela interferência do outro. Assim, Milene (E2), colocando-se nesse processo, se constitui no sujeito no qual Denis (P1) se ancora na busca de sentidos. Ao chamar a atenção para a resposta que Janaína (P5) dá ao questionamento sobre o grupo de pessoas que Simbad havia encontrado após adentrar os portões do palácio, Milene (E2) incita Denis (P1) a se confrontar com sua posição de escriba: "Você viu o que ela disse?". No entanto, somente depois de ser marcado pela fala de Milene (E2) - "Ele viu homem com roupa elegante", Denis (P1) acrescenta sujeito e verbo ao objeto já registrado: "Ele viu homem"3.

\footnotetext{
${ }^{3}$ Em fonte Arial aparecem os textos escritos pelos participantes surdos
} 
A cena aqui apresentada se desdobra entre negociações e, assim, frente ao registro de Denis (P1), Dalton (P2) questiona: "Muitos homens ou um?", fato que também leva os outros participantes ao mesmo questionamento, numa tentativa de contextualizar o escriba, por meio da colaboração e da orientação. Observamos que, mesmo após a insistência dos parceiros e de maneira mais incisiva por parte de Dalton (P2) - que assume uma posição de professor - "Um homem ou muitos homens?", Denis (P1) ainda resiste à refacção do texto. Apesar de efetuar o novo registro marcado pelas vozes de seus pares, Denis (P1) somente o faz após Danilo (E3) reforçar tais intervenções: "Então, mas você viu o que ele perguntou? Um homem (não) muitos homens". Ou ainda, enfatizando a interferência de Janaína (P5) nesse episódio, Danilo (E3) marca sua presença como referencial para que Denis (P1) realize o registro sugerido pelos pares: "Ó, ela falou que são vários". A despeito do empoderamento dos participantes surdos que já desponta quanto às sugestões e orientações, o processo da produção textual ainda é grifado pela figura do educador como referência.

O lugar desse processo é a interlocução entre sujeitos que se constituem em outros para seus interlocutores, constituindo-os assim como sujeitos, num constante movimento: um movimento que implica em incorporação/tomada da palavra do outro ao mesmo tempo em que dela se afasta, contrapondo-se a ela para torná-la palavra própria (MAYRINK-SABINSON, 2006, p. 41).

A referência que os participantes surdos buscam nos educadores faz parte do processo de constituição de sujeitos da linguagem, uma vez que, para se constituírem como tal, precisam vivenciar, de acordo com Mayrink-Sabinson (2006), um necessário encontro e contraponto com os outros. Porém, esses "outros" buscados pelos participantes surdos para sua constituição de sujeitos da escrita ainda são representados, nas sequências analisadas, pela figura do educador, que dirige os movimentos da interlocução. Nota-se que Denis (P1) reluta, aparentando certa resistência em relação à sugestão dos pares e só assente a esta quando Danilo (E3) a avaliza.

Nessa sequência, é possível observar o educador ainda sublinhando o texto escrito e produzido pelos participantes surdos, exercendo o papel do adulto letrado, de que nos fala Mayrink-Sabinson (2006, p. 115), "com o qual a criança interage" e, como representante de uma escrita confiável, concorre "para o estabelecimento do espaço e dos limites aos movimentos da criança no seu processo de constituição de uma representação escrita para a linguagem". Nas tomadas aqui analisadas, apesar de não se tratar de crianças, fica bastante claro como os participantes surdos ainda se ancoram nos educadores para a realização dessa atividade de escrita. Assim, somente respaldado pela autoridade de adulto letrado de Danilo (E3), Denis (P1) sente-se confortável para registrar a sugestão que o parceiro sinaliza: "Apaga homem e escreva o-s homens". Percebe-se aqui a centralidade da figura do professor em sala de aula, resquício da didática instrumental em que o professor retém o saber e o aluno imita (CANDAU, 2013).

(C) ETD- Educação Temática Digital Campinas, SP $\quad$ v.20 n.4 $\quad$ p.1076-1095 out./dez. 2018 
Pela análise aqui empreendida, apesar da predominância da ação do educador, observa-se o empenho deste em desenvolver, por meios das interações, a competência de expressão dos participantes surdos. O empenho do educador caracteriza-se pelas oportunidades de fala/participação dadas aos surdos. Dentre as ações do educador destacam-se as questões chamando a atenção dos participantes surdos à observação da opinião dos outros ("Você viu o que ela disse?). Ou, ainda, quando frisa o comentário de um conclamando os demais ao reexame de suas opiniões ("Então você viu o que ele perguntou?"; “Ó, ela falou que são vários"). Nesse sentido, é importante registrar a particularidade do processo de construção da sequência escrita pelos pares surdos em um ambiente propício à aprendizagem. As sutis diferenças na organização da interação entre os participantes têm importante efeito quanto à aprendizagem e ao ensino (ERICKSON, 2001). Desse modo, a qualidade das interações desenvolvidas nas oficinas, ressaltando o papel do educador na promoção do processo de autonomia dos participantes surdos, pode oportunizar situações positivas de envolvimento com a aprendizagem. Isto é o que investigaremos a seguir.

Tomando a palavra, os pares surdos

Partindo do princípio de que a interlocução é o ponto fundamental para o desenvolvimento da linguagem (oral, sinalizada ou escrita), entendemos que a qualidade das relações intersubjetivas travadas nas oficinas foi essencial para o desenvolvimento dos participantes surdos em relação à escrita. Nesse sentido, destacamos duas cenas (cenas 2 e 3) que apresentam o movimento dos participantes surdos tomando a palavra. $O$ educador ouvinte, como mediador na construção do conhecimento, estimula os participantes surdos a ocuparem os espaços discursivos.

QUADRO 3 - Transcrição da cena 2

\begin{tabular}{|c|c|c|c|}
\hline $\begin{array}{l}\text { Quem } \\
\text { sinaliza }\end{array}$ & Tradução & $\begin{array}{l}\text { Para quem } \\
\text { sinaliza }\end{array}$ & $\begin{array}{l}\text { Texto escrito produzido pelos } \\
\text { participantes surdos } \\
\text { Escribas: P1 e P2 }\end{array}$ \\
\hline E2 & $\begin{array}{l}\text { Que palavra podemos colocar entre } \\
\text { "homem e roupas" para melhorar } \\
\text { essa escrita? }\end{array}$ & Todos & $\begin{array}{l}\text { Ele viu os homens roupas elegante, } \\
\text { pajens dar doces e bebinda os pessoas }\end{array}$ \\
\hline $\mathrm{P} 2$ & $\begin{array}{l}\text { Viu o homem de roupa elegante, é } \\
\text { isso? }\end{array}$ & Todos & \\
\hline E2 & Qual palavra colocar aqui? & Todos & \\
\hline P4 & O-S? Não é? A-S? & E2 & \\
\hline P3 & Falta uma palavra A-S? A-S? & P4 & \\
\hline $\mathrm{P} 2$ & C-D-O...O-S & E1 & \\
\hline P5 & Ele viu homens C-O-M. & P1 & \\
\hline P3 & Isso, C-O-M! & P1 & $\begin{array}{l}\text { Ele viu os homens com roupas } \\
\text { elegante, pajens dar doces e bebinda } \\
\text { os pessoas }\end{array}$ \\
\hline
\end{tabular}

Fonte: Elaborado pelos autores.

(C) ETD- Educação Temática Digital Campinas, SP v.20 n.4 p.1076-1095 out./dez. 2018 
O episódio de refaç̧ão textual, analisado na cena 2 , marca o posicionamento do educador, que encoraja os participantes surdos a modificações na escrita produzida. Mediante o texto "Ele viu os homens roupas elegante, pajens dar doces e bebidas os pessoas", Milene (E2) estimula os participantes com a seguinte questão: "Que palavra podemos colocar entre homem e roupa para melhorar essa escrita?". Ao tomar tal atitude, Milene (E2) abre caminhos para que os participantes surdos negociem, predispondo-os ao exercício de trocas de conhecimentos, alargando o ambiente interacional da aprendizagem. Se, por um lado, essa atitude oportunizou a negociação entre os surdos, por outro, poderia intimidá-los ao se verem diante da falta de um elemento no texto, o qual desconheciam. Todavia, foi nesse contexto propício ao discurso que os participantes surdos contribuíram cada um com seus saberes e intuições, arriscando-se entre artigos e preposições. Observam-se interferências mútuas, uma vez que a opção dada por um leva o outro a repensar sua hipótese. Essa ação, de caráter dialógico, que um sujeito pratica em relação ao outro, tem a ver com o ativismo de Bakhtin (2006), que provoca, questiona, discorda e interfere no diálogo interior do outro sem, no entanto, apagar a voz do outro. Ainda, é interessante se voltar ao fato de que a opção acertada, quanto à inserção da preposição, veio de um dos participantes surdos, deixando clara a movimentação deste tomando a palavra e dirigindo o texto. Assim, é o dizer de um participante surdo que norteia o referido procedimento, adquirindo o valor da intervenção que o educador vinha exercendo.

Um movimento em direção à autonomia, proporcionado pelo educador que deixa os participantes surdos tomarem decisões, pode ser resgatado na sequência da cena 3 envolvendo discussões sobre pontuação.

Quadro 4 - Transcrição da cena 3

\begin{tabular}{|c|c|c|c|c|}
\hline $\begin{array}{l}\text { Quem } \\
\text { sinaliza }\end{array}$ & Tradução & $\begin{array}{l}\text { Para } \\
\text { quem } \\
\text { sinaliza }\end{array}$ & Observação do tradutor & $\begin{array}{c}\text { Texto escrito } \\
\text { produzido pelos } \\
\text { participantes surdos } \\
\text { Escriba: P6 }\end{array}$ \\
\hline P2 & $\begin{array}{l}\text { Coloca o } \\
\text { ponto final? }\end{array}$ & E2 & $\begin{array}{l}\text { P2 pergunta várias vezes para E2 se pode } \\
\text { colocar o ponto final, na última vez ele toca } \\
\text { com o indicador direito a palma da mão } \\
\text { esquerda, decidindo-se pelo ponto. }\end{array}$ & $\begin{array}{l}\text { Chefe navio aviso jogar } \\
\text { ancora água }\end{array}$ \\
\hline E2 & Avisa ele. & P2 & & \\
\hline P2 & $\begin{array}{l}\text { Coloca o } \\
\text { ponto final. }\end{array}$ & P6 & & \\
\hline P5 & $\begin{array}{l}\text { Coloca a } \\
\text { vírgula. }\end{array}$ & P6 & & \\
\hline P5 & $\begin{array}{l}\text { Coloca a } \\
\text { vírgula. }\end{array}$ & P6 & & \\
\hline P2 & $\begin{array}{l}\text { Coloca o } \\
\text { ponto final. }\end{array}$ & P6 & & \\
\hline P6 & $\begin{array}{l}\text { Coloca a } \\
\text { vírgula? }\end{array}$ & P5 & & \\
\hline P5 & $\begin{array}{l}\text { Coloca } \\
\text { virgula }\end{array}$ & P6 & $\begin{array}{l}\text { Entre as duas opções oferecidas, P6 decide } \\
\text { pela vírgula. }\end{array}$ & $\begin{array}{l}\text { Chefe navio aviso } \\
\text { jogar ancora água, }\end{array}$ \\
\hline
\end{tabular}

(C) ETD- Educação Temática Digital Campinas, SP v.20 n.4 p.1076-1095 out./dez. 2018 
Fonte: Elaborado pelos autores.

Com o objetivo de orientar Miguel (P6) na continuação de um período, Dalton (P2) indaga Milene (E2): “Coloca o ponto final?". Após insistir na pergunta e, sem a esperada manifestação do educador, o participante decide pelo ponto final. É de se notar que somente após a decisão de Dalton (P2) é que Milene (E2), no turno seguinte, dando seu aval, se manifesta: "Avisa ele". Nesse momento, entra em jogo Janaína (P5), sugerindo uma vírgula. O que pareceu, num primeiro momento, desestabilizar o escriba, torna-se um episódio de manifestação de capacidade de atuação autônoma, quando este opta pelo registro da vírgula. Vale assinalar o episódio como deslocamento dos participantes surdos em direção à autonomia da escrita, em cujo lugar de interação e aprendizagem os sujeitos se sentem autorizados para escrever e predispostos a aprender. Destaca-se aqui o papel do educador deslocando "poder" para os participantes que começam a protagonizar decisões.

Protagonizando a escrita, os pares surdos

A construção e a defesa de projetos de dizer como fruto de controvérsias e conflitos podem ser observadas na cena 4 . O processo da reescrita coletiva havia se estabelecido, no início, muito mais pelo consenso entre pares, com aceitação, muitas vezes sem a seleção das propostas apresentadas. Destacamos aqui um episódio de interlocução que demonstra a defesa de diferentes concepções de compreensão textual em que participantes surdos tomam a rédea das ações linguísticas.

QUADRO 5 -Transcrição da cena 4

\begin{tabular}{|c|l|c|c|}
\hline $\begin{array}{c}\text { Quem } \\
\text { sinaliza }\end{array}$ & \multicolumn{1}{|c|}{ Tradução } & $\begin{array}{c}\text { Para quem } \\
\text { sinaliza }\end{array}$ & \multicolumn{1}{|c|}{$\begin{array}{c}\text { Texto escrito produzido pelos } \\
\text { participantes surdos } \\
\text { Escribas: P6 e P2 }\end{array}$} \\
\hline P2 & Não, coloca A-F-O-G-A & P6 & Eu afoga \\
\hline P5 & $\begin{array}{l}\text { O quê? Apaga, ele não afogou, não } \\
\text { morreu. }\end{array}$ & P6 & \\
\hline P5 & Não afogou & P2 & \\
\hline P2 & Afogou sim, S-I-M & P5 & \\
\hline P5 & $\begin{array}{l}\text { Ele encontrou... Ele nadou depois } \\
\text { encontrou um barril. }\end{array}$ & P2 & \\
\hline P2 & Isso. & P5 & Eu afoga depois encontrei o barril \\
\hline
\end{tabular}

Fonte: Elaborado pelos autores.

Mediante o registro de Dalton (P2): "Eu afoga", Janaína (P5), no turno seguinte, explicita seu estranhamento: "O quê? Apaga, ele não afogou, não morreu" e, mais adiante, completa: "Ele encontrou... Ele nadou depois encontrou um barril". Entre argumentos, contra-argumento e refutações de propostas, consubstancia-se um trabalho reflexivo de leitura e de escrita. 0 fato aqui discutido remete a questões de produção e recepção textual uma vez que envolve experiências e percepções individuais na construção de sentidos em torno do verbo afogar. A solução de Dalton (P2), ao registrar "Eu afoga depois encontrei o barril", aponta para um intrincado processo dialógico em que não cabe uma simples síntese, mas que é de

(C) ETD- Educação Temática Digital Campinas, SP v.20 n.4 p.1076-1095 out./dez. 2018 
combinação de vozes em que elas são acordes. De acordo com Bakhtin (2006), não se trata de uma conclusão monológica, mas de um evento de interação de vozes.

Como vimos demonstrando, os deslocamentos dos participantes surdos são caracterizados por posicionamentos ativos, que, ao partilhar, somam conhecimentos. Nesse sentido, um episódio que revela um sujeito retomando o fio da argumentação do outro para dar novos rumos à enunciação está descrito na cena 5 .

QUADRO 6 - Transcrição da cena 5

\begin{tabular}{|c|c|c|c|}
\hline $\begin{array}{c}\text { Quem } \\
\text { sinaliza }\end{array}$ & Tradução & $\begin{array}{c}\text { Para quem } \\
\text { sinaliza }\end{array}$ & $\begin{array}{c}\text { Texto escrito produzido } \\
\text { pelos participantes surdos } \\
\text { Escriba: P1 }\end{array}$ \\
\hline P2 & O homem O-H-O-M-E-M & P1 & $\begin{array}{l}\text { O simbad encontrou ilha } \\
\text { verdade depois encontrou } \\
\text { homem }\end{array}$ \\
\hline P1 & Não... espera. & P2 & \\
\hline P1 & $\begin{array}{l}\text { O homem encontrou uma ilha, mas não } \\
\text { encontrou o homem, encontrou um cavalo, ele } \\
\text { encontrou o cavalo do homem. }\end{array}$ & Todos & \\
\hline P1 & A ou O?... cavalo & Todos & \\
\hline P2 & 0 , não sei. & $\mathrm{P} 2$ & \\
\hline P7 & A cavalo, é A & P2 & $\begin{array}{l}\text { O simbad encontrou ilha } \\
\text { verdade depois encontrou o } \\
\text { cavalo }\end{array}$ \\
\hline
\end{tabular}

Fonte: Elaborado pelos autores.

Dirigindo-se pela narração de Dalton (P2), o participante Denis havia registrado: "O Simbad encontrou ilha verdade depois encontrou homem". Porém, no turno seguinte, o escriba toma a palavra interferindo no discurso de Dalton (P2): "Não, espera", aludindo ao fato de que Simbad teria encontrado primeiro o cavalo do homem. Na esteira de Bakhtin/Volochinov (2010), pode-se afirmar que muito além da recuperação da sequência lógica do texto, o episódio demonstra o trabalho de um sujeito infiltrando suas réplicas, seus pareceres, sua compreensão no discurso do outro, empenhando-se para desfazer a estrutura dada pelo discurso de Dalton (P2). É nessa direção, ainda com Bakhtin, que nos deparamos com um sujeito (Denis - P1) que se coloca na enunciação como aquele que é capaz de, se não apagar as fronteiras do discurso de Dalton (P2), colori-lo com seus tons, defendendo sua opinião.

\section{CONSIDERAÇÕES FINAIS}

No contexto das interlocuções, interessou-nos o fenômeno social da interação verbal estabelecido entre participantes surdos e educadores ouvintes, como meio de observação das negociações do processo da reescrita de uma história de aventura empreendido pelos sujeitos surdos. Partindo do princípio de que cada um define suas enunciações pelos próprios acentos apreciativos, porém, dirigido pelo meio que alarga dialeticamente o horizonte social, rastreamos os deslocamentos dos participantes das oficinas no processo de interlocução que

$$
\text { (C) ETD-Educação Temática Digital Campinas, SP } \quad \text { v.20 n.4 } \quad \text { p.1076-1095 out./dez. } 2018
$$


presidiu a produção textual escrita. As interações que promoveram, de fato, o desenvolvimento da produção textual escrita foram as oportunidades de negociações abertas pelos educadores que levaram os participantes surdos ao reexame de seus registros e o encorajamento para se arriscarem além daquilo que sabiam na escrita de uma língua diferente da sua.

A partir da análise das cinco cenas, podemos observar o movimento dos participantes surdos em direção à independência no percurso da escrita. De início, o educador ouvinte, destacando-se no processo, organiza e dirige as interações, promovendo o desenvolvimento das competências expressivas dos participantes surdos. Nesse sentido, o educador provoca um ambiente propício à aprendizagem. Essas interações, tendo o educador o papel de promotor dos processos ali desencadeados, geram situações favoráveis à autonomia dos participantes surdos.

É, pois, nesse contexto que os educadores ouvintes, enquanto mediadores na construção do conhecimento, assumem menos responsabilidades em relação à escrita favorecendo que os sujeitos surdos ocupem mais e mais o espaço discursivo. Esse recuo cria nas interações espaços que os participantes surdos querem e podem ocupar. Sendo assim, no contexto de oficinas, agora o educador ouvinte se constitui no outro que instiga os participantes surdos, dando-Ihes realce nas ações, enquanto estes buscam se constituir pelas pegadas de seus pares. O que se observou nos movimentos registrados foram os deslocamentos instaurados: do educador como suporte total à confiança depositada nos pares surdos, que se apoiam. Destaca-se, aqui, a geração de saberes individual e coletiva. Saberes partilhados que desencadearam um processo rumo ao protagonismo dos surdos dirigindo suas próprias ações na produção de linguagem escrita.

Ressalta-se que as práticas e as formações discursivas nas oficinas, voltadas ao desenvolvimento dos mecanismos de produção e compreensão dos discursos, concretizaramse por meio da língua de sinais como a base para o registro escrito. A língua de sinais, na emergência da proposta bilíngue, foi imprescindível para a construção da competência linguística dos participantes surdos quanto à leitura e escrita em português. Fica patente a necessidade de a Língua Portuguesa ser, efetivamente, tratada como segunda língua, em que a língua de sinais ocupe o lugar central desse processo.

O desenvolvimento da escrita dos participantes surdos foi facultado pelas interações mediadas pela língua de sinais como consequência de práticas discursivas que se consubstanciaram em possibilidades de ações quanto ao uso da linguagem. O resultado desta pesquisa mostra que um trabalho pela perspectiva bilíngue e que privilegie ações coletivas favorece a emergência de saberes individuais de forma mais segura que os modos tradicionais, revelando a capacidade de aprender dos sujeitos surdos quando em contextos propícios de interação. O caráter dessa interação, ou seja, o modo da organização da interação estabelecido nas oficinas promoveu situações de envolvimento dos participantes

(C) ETD- Educação Temática Digital Campinas, SP $\quad$ v.20 n.4 $\quad$ p.1076-1095 out./dez. 2018 
surdos com a aprendizagem, favorecendo o desenvolvimento das relações entre linguagem, discurso e escrita. Isso aponta para a necessidade premente de reflexão em torno das ações que a escola regular vem desenvolvendo como trabalho voltado à surdez.

\section{REFERÊNCIAS}

BAKHTIN, Mikhail. Estética da criação verbal. 4. ed. São Paulo: Martins Fontes, 2006. 476 p. ISBN 85-336-1807-7.

BAKHTIN, Mikhail; VOLOCHÍNOV Valentin Nikolaevich. Marxismo e filosofia da linguagem: problemas fundamentais do método sociológico na ciência da linguagem. 14. ed. São Paulo: Hucitec, 2010. 203 p. ISBN 978-85-271-0041-0.

CANDAU, Vera Maria (Org.). Rumo a uma nova didática. 23. ed. Petrópolis, RJ: Vozes, 2013. 208 p. ISBN 9788532604347.

ERICKSON, Frederick. Prefácio. In: COX, Maria Inês Pagliarini; ASSIS-PETERSON, Ana Antônia. Cenas de sala de aula. Campinas: Mercado das Letras, 2001. 272 p. ISBN 85 85725-67-2.

FÉLIX, Ademilde. O papel da interação no processo de ensino-aprendizagem de Português para alunos surdos em uma escola inclusiva. Trabalhos em Linguística Aplicada, Campinas, v. 48, n. 1, p. 119-131, jan./jun. 2009. Disponível em:

http://www.scielo.br/scielo.php?script=sci arttext\&pid=S0103-18132009000100009 . Acesso em: 10 jan. 2018.

FERNANDES, Sueli. Educação de surdos. 2. ed. Curitiba: Ibepex, 2011. 159 p. ISBN 9788582120132.

HOLEINONE, Peter. As sete viagens de Simbad, o marujo e outras histórias. Trad. Denise Perrotti. São Paulo: Paulinas, 1998. 53 p. ISBN 85-7311-924-1.

LACERDA, Cristina Broglia Feitosa. A inclusão escolar de alunos surdos: o que dizem alunos, professores e intérpretes sobre esta experiência. Cadernos CEDES, v. 26, n. 69, p.163-184, Campinas, maio/ago., 2006. Disponível em:

http://www.scielo.br/scielo.php?script=sci arttext\&pid=S0101-32622006000200004 . Acesso em: 2 maio. 2017.

LACERDA, Cristina Broglia Feitosa; SANTOS, Lara Ferreira; CAETANO, Juliana Fonseca. Estratégias metodológicas para o ensino de alunos surdos. In: LACERDA, Cristina Broglia Feitosa; SANTOS, Lara Ferreira. Tenho um aluno surdo, e agora? Introdução à Libras e educação de surdos. São Carlos: EDUFSCar, 2013. 254 p. ISBN 978-85-7600-307-6.

LODI, Ana Cláudia Balieiro. Ensino da Língua Portuguesa como segunda língua para surdos: impacto na Educação Básica. In: LACERDA, Cristina Broglia Feitosa; SANTOS, Lara Ferreira. Tenho um aluno surdo, e agora? Introdução à Libras e educação de surdos. São Carlos: EDUFSCar, 2013. 254 p. ISBN 978-85-7600-307-6.

LODI, Ana Cláudia Balieiro; BORTOLOTTI, Elaine Cristina; CAVALMORETI, Maria José Zanatta Letramentos de surdos: práticas sociais de linguagem entre duas línguas/culturas.

Bakhtiniana, Revista de estudos do Discurso, São Paulo, v. 9, n. 2, p. 131-149,

(C) ETD- Educação Temática Digital Campinas, SP $\quad$ v.20 n.4 $\quad$ p.1076-1095 out./dez. 2018 
ago./dez.2014. Disponível em: http://www.scielo.br/pdf/bak/v9n2/a09v9n2.pdf . Acesso em: 21 set. 2017.

MAYRINK-SABINSON, Maria Laura Trindade. Um evento singular. In: ABAURRE, Maria Bernadete Marques; FIAD, Raquel Salek; MAYRINK-SABINSON, Maria Laura Trindade. Cenas de aquisição da escrita: o sujeito e o trabalho com o texto. Campinas: Associação de Leitura do Brasil (ABL)/ Mercado de Letras, 2006, 200 p. ISBN 85 85725-38-9.

MAYRINK-SABINSON, Maria Laura Trindade. O papel do interlocutor. In: ABAURRE, Maria Laura Trindade; FIAD, Raquel Salek; MAYRINK-SABINSON, Maria Laura Trindade. Cenas de aquisição da escrita: o sujeito e o trabalho com o texto. Campinas: Associação de Leitura do Brasil (ABL): Mercado de Letras, 2006, 200 p. ISBN 85 85725-38-9.

PEREIRA, Gislene Alves et al. Alfabetização x letramento de surdos no ensino regular: revisão de literatura. Humanidades, Montes Claros, v.5, n.2, jul. 2016. Disponível em:

http://www.revistahumanidades.com.br/arquivos up/artigos/a105.pdf . Acesso em: 15 jun. 2018.

ROJO, Roxane; CORDEIRO, Glaís Sales. Apresentação - gêneros orais e escritos como objetos de ensino: modo de pensar, modo de fazer. In: SCHNEUWLY, Bernard; DOLZ, Joaquim.

Gêneros orais e escritos na escola. 2. ed. Trad. Roxane Rojo e Glaís Sales Cordeiro. Campinas: Mercado de Letras, 2010, 239 p. ISBN 85-7591-032-9.

SCHNEUWLY, Bernard; DOLZ, Joaquim. Os gêneros escolares: das práticas de linguagem aos objetos de ensino. In: SCHNEUWLY, Bernard; DOLZ, Joaquim et al. Gêneros orais e escritos na escola. 2. ed. Trad. Roxane Rojo e Glaís Sales Cordeiro. Campinas: Mercado de Letras, 2010, 239 p. ISBN 85-7591-032-9.

SILVA, Ivani Rodrigues. Perspectiva de educação intercultural bilíngue para surdos. Estudos Linguísticos e Literários. Salvador, v. 1, n.50, p. 120-144, jul/dez, 2014. Disponível em: https://portalseer.ufba.br/index.php/estudos/article/view/14815/10161 . Acesso em: 11 jan. 2018.

STREIECHEN, Eliziane Manosso; KRASE-LEMKE, Cibele. Análise da produção escrita de surdos alfabetizados com proposta bilíngue: implicações para a prática pedagógica. Revista Brasileira de Linguística Aplicada, Belo Horizonte, v.14, n. 4, p. 957-985, out/dez, 2014. Disponível em: http://www.scielo.br/scielo.php?script=sci abstract\&pid=S198463982014000400009\&lng=es\&nrm=iso\&tlng=en . Acesso em: 11 jan. 2018.

SVARTHOLM, Kristina. 35 anos de educação bilíngue de surdos - e então? Educar em Revista, Curitiba, Edição Especial n. 2, p. 33-50, 2014. Disponível em: http://revistas.ufpr.br/educar/article/view/37228 . Acesso em: 10 jan. 2018.

*Revisão gramatical do texto sob responsabilidade de:

Lara Padilha - E-mail: lararevisoes@gmail.com 